\title{
Trust we must
}

\author{
Asking people to trust scientists is not enough in times of doubt. Scientists must trust the people too: \\ to make decisions for themselves, once they know the best available evidence.
}

Science is facing a stiff headwind, with budget cuts and dwindling respect for factual arguments. Scientific evidence has lost its once unique authority in explaining the world. This is especially true in politically relevant fields, including many of the Earth sciences. Researchers working on environmental issues, climate change or sustainability can no longer take it for granted that an evidence-based scientific approach will inform policy-making. A discussion panel at the General Assembly of the European Geosciences Union (EGU) (http:// client.cntv.at/egu2017/us3) in Vienna this April - in the week following the March for Science - was held on the topic of "Make Facts Great Again: how can scientists stand up for science?"

The need to regain the public's trust in science ran through the debate as a recurrent theme. Transparency is clearly a key ingredient. As a vivid illustration of this point, David King, the UK government's chief scientific advisor during the country's foot-and-mouth epidemic in 2001, noted that public approval of science took a sharp upward turn when he decided to make his advice to the government publicly available on a regular basis. But in the world as it is today, transparency alone is not enough to win over a sceptical audience.

Science will be respected as a contributor of evidence-based statements - facts, as it were - only if scientists are seen as impartial investigators. The role does not sit easy with advocacy. This dilemma was widely discussed in the run-up to the March for Science. Fears that the march could be seen as politically partisan led to criticism (http:// go.nature.com/2qn9slB). The fierceness of the debate invites critical reflection. Perhaps the false notion that science is a left-wing endeavour is spreading not only as a result of discreditation of research by those with vested interests, but also as a result of the way many scientists interact with the public, which is not always apolitical. The tensions that Republican scientists in the US experience with their liberal colleagues (http://go.nature. $\mathrm{com} / 2 \mathrm{rlCEqI}$ ) are indicative of a lack of impartiality of university culture. Indeed, the title of the EGU debate, too, speaks not only against opposition to reason but at the same time carries connotations against political conservatism.

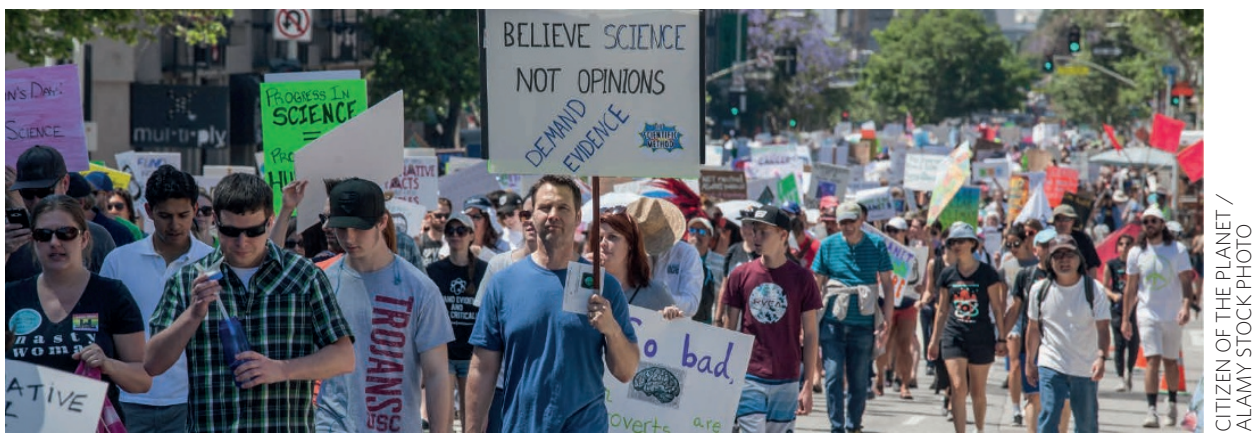

There is an important distinction to be made. Advocacy from scientists for an evidence-based approach to decision making is independent of political views of the world. It is therefore within the remit of scientists who strive to be impartial. At Nature Geoscience, we have always encouraged scientists to engage in a dialogue with the public and policy-makers (http://go.nature.com/2rbd6A4), and indeed the broad dissemination of research to the public is part of our mission.

There is, however, a fundamental conflict between providing impartial information and engaging in advocacy for specific policy solutions or for the prioritization of one policy goal, say food security, over another, such as preservation of biodiversity. When scientists publicly advocate on political issues - for example, arguing that "in global governance, climate stabilization must be placed on par with economic development, human rights, democracy and peace" (Science 355, 1269-1271; 2017) - their personal opinions will enter the public discourse under the heading of 'scientists say that ... ? Yet science cannot help with the question of whether peace and climate stabilization are, or are not, equally important. Such statements could therefore lead to the false - and potentially counter-productive - impression that science is ultimately political.

The Intergovernmental Panel on Climate Change (IPCC) is clear on this distinction. The panel's very existence and the fact that its key findings are approved by the participating governments ensure that the evidence on climate change is noted and acknowledged by policy-makers. As such, the IPCC's work directly supports an approach to policymaking that takes the scientific evidence into account. The IPCC draws the line at this point: it firmly declares its work as being "policy- relevant and yet policy-neutral, never policyprescriptive" (http://go.nature.com/2rbwIny).

Such restraint is critically important. When, during the pro-Brexit campaign, one British politician (in)famously stated that "people in this country have had enough of experts," he hit a nerve. But people like to understand the world around them; popular science books and newspaper articles on science (including in the tabloids) are well read. What the public probably do not like is - put bluntly - being told what to think. Of course, scientists are entitled to have and discuss opinions just like any other citizen of the world. But when their scientific expertise grants them prominent roles in public forums, the most appropriate role for scientists and other experts is to share their evidence-based insights, complete with caveats and uncertainties. With the evidence in hand, policy-makers and the public are then empowered to form opinions on the prioritization of pressing problems, and hence on the best way to manage the planet.

In times of urgency, it is tempting for scientists to cut the opinion-forming stage short and weigh in to accelerate progress towards policy implementation. But that strategy can easily backfire: it sows scepticism among those who feel excluded.

Scientists should by all means speak out in favour of an evidence-based approach. They should strive to communicate their understanding of the world, and attract attention to issues that need to be managed, and to potential dangers to society. But ultimately, there is no way around trusting the public and their elected leaders to decide what should be done about these. That is the core of democracy, after all.

Corrected after print: 6 June 2017 


\section{Correction}

In the Editorial 'Trust we must' (Nat. Geosci.

10,$395 ; 2017$ ) we incorrectly referred to the European Geosciences Union as the European

Geophysical Union. This has been corrected

after print on 6 June 2017. 